Article

\title{
Heterogeneous Nanomagnetic Catalyst from Cupriferous Mineral Processing Gangue for the Production of Biodiesel
}

\author{
Wighens I. Ngoie ${ }^{1,2}$ (D), Pamela J. Welz ${ }^{1}$ (D), Daniel Ikhu-Omoregbe ${ }^{2}$ \\ and Oluwaseun O. Oyekola $2, *$ (D) \\ 1 Institute of Biomedical and Microbial Biotechnology, Cape Peninsula University of Technology, \\ Cape Town 7535, South Africa; wghngoie@gmail.com (W.I.N.); welzp@cput.ac.za (P.J.W.) \\ 2 Department of Chemical Engineering, Cape Peninsula University of Technology, Cape Town 7535, \\ South Africa; IkhuOmoregbeD@cput.ac.za \\ * Correspondence: oyekolas@cput.ac.za; Tel.: +27-(0)-21-959-6799
}

Received: 14 October 2019; Accepted: 26 November 2019; Published: 10 December 2019

\begin{abstract}
The commercialisation of biodiesel as an alternative energy source is challenged by high production costs. The cost of feedstock, catalyst and separation of the dissolved catalyst (homogeneous catalyst) from the product are the major contributors to the total manufacturing cost of biodiesel. This study investigated the potential of a heterogeneous catalyst produced from mineral processing waste for biodiesel production. Tailings from the concentration of cupriferous minerals served as the starting material for synthesis of the catalyst. The nanomagnetic catalysts were prepared using co-precipitation (CMCO) and sol-gel (CMSG) methods, combined with zero-valent iron nanoparticles (ZVINPs) to form a hydride catalyst (CMSG/ZVINPs). Catalyst properties were assessed using SEM, TEM, BET and EDX. The catalyst activity was enhanced by a large number of basic sites that were afforded by the presence of calcite and magnesite. Good surface areas and particle sizes of $58.9 \mathrm{~m}^{2} / \mathrm{g}$ and $15.4 \mathrm{~nm}$, and $52.6 \mathrm{~m}^{2} / \mathrm{g}$ and $16.9 \mathrm{~nm}$ were observed for the catalysts that were prepared using the CMSG and CMCO methods, respectively. $173 \mathrm{emu} / \mathrm{g}$ mass magnetisation was obtained for CMSG/ZVINPs, which was sufficient for the catalyst to be regenerated and reused for biodiesel production by exploiting the magnetic properties. The maximum yield obtained with this catalyst was $88 \%$ and an average of $27 \%$ decrease in biodiesel yield was observed after four reaction cycles. The physicochemical properties of the biodiesel produced complied with the ASTM standard specification. The results showed that mineral processing tailings are a viable starting material for catalyst preparation in biodiesel production.
\end{abstract}

Keywords: biodiesel; heterogeneous nano-magnetic catalyst; edible oil wastewater sludge

\section{Introduction}

The main purpose of ore beneficiation in the mineral processing industries is to increase the metal content. Pyrometallurgy or hydrometallurgy processes are employed depending on their nature (sulfide, oxides, or mixed), or on the initial metal purity in the ore [1]. Hydrometallurgy is the most suitable process for low-grade ores [2]. The essential concentration operation after the ore has been reduced into an appropriate size, for valuable mineral liberation from the unwanted material (gangue), is froth flotation. This involves the chemical separation of gangue from the mineral (fraction containing the valuable metal of interest) [1,2]. Gangue can be acidic (mainly containing silica and quartz), as in the case of sulfide ores or alkaline (mainly dolomite and calcite), as found in oxide and mixed ores [2]. Dolomite is mainly comprised of calcium and magnesium, and it is the dominant material in the tailings effluent from froth flotation process [2,3]. 
Catalysts that are used for biodiesel production are classified vis-à-vis their mode of action and reaction phases, into homogeneous, heterogeneous, and enzymatic catalysts [4]. The selection of a catalyst for any process depends on a number of parameters, including, cost, availability, activity, selectivity, and stability [5,6]. Homogeneous-catalysed transesterification, which is the conventional method that is used to produce biodiesel from vegetable oils, utilises potassium hydroxide (KOH) or sodium hydroxide $(\mathrm{NaOH})$ as homogenous base catalysts to produce high yields of biodiesel under moderate conditions. This approach is impaired by soap formation in the presence of water, especially when low-cost feedstocks are utilised. This results in separation difficulties during biodiesel purification $[4,7]$. Magnesium oxide $(\mathrm{MgO})$ and calcium oxide $(\mathrm{CaO})$ have been shown to have high catalytic activities, good robustness, and favourable resistance to acid [8]. It is envisaged that the use of heterogeneous magnetic catalysts produced from $\mathrm{MgO}$ and $\mathrm{CaO}$ for biodiesel production will enable more efficient mass transfer than conventional heterogeneous catalysts due to the high surface area and ferromagnetic properties of the nanoparticles. This might reduce catalyst loading and improve the biodiesel yield, ultimately reducing biodiesel production costs [9]. Amani et al. [8] identified $\mathrm{MgO}$ as a promising heterogeneous catalyst for the transesterification of soybean and vegetable oils into biodiesel, with a maximum biodiesel yield of $79 \%$ with $10 \mathrm{wt} . \%$ catalyst loading. It has been shown that these oxides do not require magnetic cations to become ferromagnetic, and a novel type of magnetism, which is tentatively called interface magnetism, has been recognised. Under certain conditions, magnetism arises in the absence of transition metal elements, and this phenomenon confers potential ferromagnetic properties to $\mathrm{MgO}$ and $\mathrm{CaO}[8,10]$.

The use of nanomagnetic catalysts is a promising alternative in the transesterification process, because the magnetic separation generally avoids the loss of catalyst and increases its reusability in comparison to filtration or centrifugation separation [11,12]. Nanomagnetic catalysts have been widely applied in the fields of photocatalysis [13], biocatalysis [14], and phase-transfer catalysis [15], in addition to a large specific surface area and high catalytic activity. Ying and Chen [16] stabilised the cells of lipase-producing Bacillus subtilis on the net of a hydrophobic carrier with $\mathrm{Fe}_{3} \mathrm{O}_{4}$ magnetic particles. for the transesterification of waste cooking oils with methanol, while Xie and Ma [17] immobilised lipase on $\mathrm{Fe}_{3} \mathrm{O}_{4}$ nanoparticles for biodiesel production. In these instances, the magnetic particles did not possess catalytic properties; they merely acted as immobilisation matrices for enhancing catalyst recovery. Ali et al. [18] synthesised a nanocatalyst of $\mathrm{CaO}$ supported by $\mathrm{Fe}_{3} \mathrm{O}_{4}$ magnetic particles using the chemical precipitation method. A maximum biodiesel yield of $69.7 \%$ was obtained under optimum conditions $\left(65^{\circ} \mathrm{C}, 300 \mathrm{~min} ., 20\right.$ methanol/oil molar ratio, and $10 \mathrm{wt} . \%$ of $\mathrm{CaO} / \mathrm{Fe}_{3} \mathrm{O}_{4}$ catalyst loading) using palm seed oil as feedstock.

The synthesis of oxide nanoparticles can be grouped into two main streams, based on the liquid-solid and gas-solid nature of the transformations [7]. Liquid-solid transformations are the most broadly used methods. Catalyst preparation aims at ensuring suitable activity, selectivity, and stability. These are related to the physical and chemical properties of the starting material, as well as the parameters that are inherent in the preparation method [19]. In this study, the CMSG and CMCO methods were investigated for the catalyst synthesis from mineral processing wastes, due to their low-cost when compared to other techniques.

The co-precipitation method (CMCO): Co-precipitation involves dissolving a salt precursor (mainly chloride or nitrate) in water or other solvents to precipitate the oxo-hydroxide $[\mathrm{O}(\mathrm{OH})]$ with the help of a base. The control of size and chemical homogeneity in the case of mixed metal oxides are difficult to achieve. This may be overcome by the use of surfactants and high-gravity reactive precipitation methods $[8,20]$.

The sol-gel method (CMSG): The method prepares metal oxides via hydrolysis of precursors, usually alkoxides in alcohol solution, resulting in the corresponding $[\mathrm{O}(\mathrm{OH})]$ group. The condensation of molecules by dehydration leads to the formation of a network of the metal hydroxide. Hydroxyl-species undergo polymerisation by condensation and form a dense porous gel. Appropriate drying and calcination lead to ultrafine porous oxides $[7,15]$. Irrespective of the preparation method 
that was used to obtain ultrafine nano-oxides, crystallisation does not follow a traditional nucleation and growth mechanism [21]. The crystallisation mechanisms may be a function of the chemical nature of the oxide and the process temperature [22].

In the conventional biodiesel production process, oil is derived from oilseed crops, which is associated with the food versus fuel dilemma [23,24]. In this study, the oil and alcohol that were employed for the transesterification reaction for biodiesel production were extracted from edible oil wastewater sludge. The heterogeneous nanomagnetic catalyst, which was used in mediating the reaction, was prepared from waste without magnetite support, in the presence of ZVINPs to enhance the catalyst mass transfer abilities during this process [23].

\section{Results and Discussion}

\subsection{Gangue Characterisation}

EDX analysis was conducted to assess the elemental composition and purity of the gangue material and the prepared catalysts. The results that were obtained from the EDX analysis of the gangue material showed predominance of magnesium (4 cps/ev) and calcium (4.2 cps/ev) (Figure 1). The predominance of magnesium or other related transitional metals in heterogeneous catalysts has been widely shown to have a positive impact on their mass transfer capabilities in the transesterification process, subsequently enhancing the biodiesel production at lower reaction rates [22].

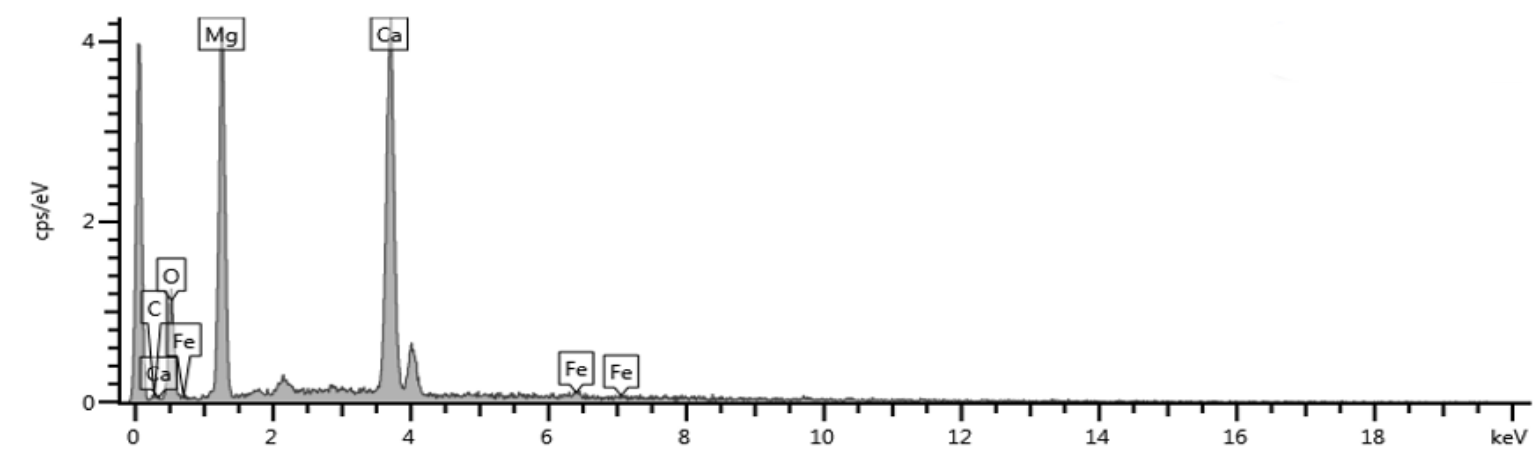

Figure 1. EDX results of the raw material (gangue) used to prepare the catalyst.

On the Linus Pauling scale, magnesium and calcium are characterised by electronegativity values of 1.32 and 1 , respectively $[25,26]$. This is an important factor that can enable the catalyst to exhibit higher basicity and improved catalytic activity for better biodiesel yield during the transesterification reaction. The peak maxima were obtained at 1.3 and $3.6 \mathrm{keV}$ for magnesium and calcium, respectively (Figure 1).

\subsection{Brunauer-Emmett-Teller (BET) Surface Area Analysis and Barrett-Joyner-Halenda (BJH) Pore Size and Volume Analysis}

The surface area of the catalysts was determined using BET analyses, while the pore size and specific pore volume were determined using the adsorption and desorption techniques (BJH analyses). Results showed that an increase in nitric acid concentration increased the surface area of all catalysts (Table 1). 
Table 1. Comparison of surface areas and pore sizes of the prepared catalysts with previous studies.

\begin{tabular}{cccc}
\hline Sample & Surface Area $\left(\mathbf{m}^{2} / \mathbf{g}\right)$ & Average Pore Size $(\AA)$ & References \\
\hline $\mathrm{CMCO}_{2}{ }^{*}$ & $52.6 \pm 0.37$ & $135.6 \pm 0.13$ & This study \\
$\mathrm{CMSG}_{3}{ }^{*}$ & $58.7 \pm 0.55$ & $169.3 \pm 0.21$ & This study \\
$\mathrm{CMSG}_{3} / \mathrm{ZVINPs}_{2}$ & $53.5 \pm 1.52$ & $148.5 \pm 0.09$ & This study \\
$\mathrm{CaO} / \mathrm{Fe}_{3} \mathrm{O}_{4}$ & 59.1 & 8.5 & {$[26]$} \\
$\begin{array}{c}\mathrm{KF} / \mathrm{Ca}-\mathrm{Mg}-\mathrm{Al} \\
\text { hydrotalcite }\end{array}$ & 108.4 & 3.7 & {$[14]$}
\end{tabular}

* Only the best results are represented in this table. Results are expressed as averages \pm standard deviation $(\mathrm{n}=3)$; With $\mathrm{CMCO}=$ Catalyst prepared using the co-precipitation method, $\mathrm{CMSG}=$ Catalyst prepared using the sol-gel method, ZVINPs = Zerovalent iron nanoparticles.

The results also indicated (Table 2) that $\mathrm{CMSG}_{3}$ had the highest surface area of $58.7 \mathrm{~m}^{2} / \mathrm{g}$. The adsorption average pore width ( 4 V/A by BET) was $169.3 \AA$ for $\mathrm{CMCO}_{2}$ with a BJH adsorption average pore width $(4 \mathrm{~V} / \mathrm{A})$ of $146.7 \AA$ and a BJH desorption average pore width (4V/A) of $148.5 \AA$, compared to $155.1 \AA$ for $\mathrm{CMSG}_{3}$ with BJH Adsorption average pore width $(4 \mathrm{~V} / \mathrm{A})$ of $135.6 \AA$ and $\mathrm{BJH}$ desorption average pore width (4 V/A) of $153.9 \AA$.

Table 2. Mass magnetisation of catalysts prepared.

\begin{tabular}{|c|c|}
\hline Catalysts & Average Mass Magnetisation (emu/g) \\
\hline $\mathrm{CMCO}_{1}$ & $153 \pm 0.71$ \\
\hline $\mathrm{CMCO}_{2}$ & $168 \pm 1.45$ \\
\hline $\mathrm{CMCO}_{3}$ & $159 \pm 0.97$ \\
\hline $\mathrm{CMSG}_{1}$ & $76 \pm 1.94$ \\
\hline $\mathrm{CMSG}_{2}$ & $91 \pm 1.06$ \\
\hline $\mathrm{CMSG}_{3}$ & $84 \pm 0.56$ \\
\hline $\mathrm{CMSG}_{3} / \mathrm{ZVINPs}_{1}$ & $134 \pm 2.52$ \\
\hline $\mathrm{CMSG}_{3} / \mathrm{ZVINPs}_{2}$ & $173 \pm 0.36$ \\
\hline $\mathrm{CMSG}_{3} / \mathrm{ZVINPs}_{3}$ & $162 \pm 1.27$ \\
\hline
\end{tabular}

The effect of synthesis methods on the surface area of CMCOs and CMSGs was significant, with $\mathrm{CMSG}_{3}$ maintaining a higher surface area when compared to the $\mathrm{CMCO}_{2}$ sample. Cross-sectional area measurements showed that all of the tested samples were mesoporous. The results that were obtained in the current study agree with previous reports. Report by Xie and Fan [27] investigated the production of biodiesel using tetra alkyl ammonium hydroxides that were immobilised on mesoporous silica as a solid catalyst. Using the co-precipitation method, the catalyst samples prepared were characterised by maximum surface area of $61 \mathrm{~m}^{2} / \mathrm{g}$. Similarly, Rashtizadeh et al. [28] and Teo et al. [29] achieved a surface area of $59 \mathrm{~m}^{2} / \mathrm{g}$ when nanocomposite and mesoporous materials containing calcium oxide were prepared.

\subsection{Microscopic Observations}

SEM micrographs at $20 \mathrm{~nm}$ scale (Figure 2A-F) show the three-dimensional (3-D) morphology of the CMCO and CMSG catalysts, while Figure 3A-F are TEM micrographs of the same catalysts at $200 \mathrm{~nm}$ scale and $5.00 \mathrm{KX}$ magnification. The catalysts prepared using the sol-gel method had a more elongated shape and uniform distribution, while those that were prepared using the co-precipitation method exhibited strong agglomeration and a higher degree of variation in size. For the CMSG catalysts, the micrographs were homogeneous microstructures (Figure 3). This can be attributed to the fact that, in the sol-gel process, the open structure of the gelatinous state formed allows for free crystal agglomeration, resulting in a more spherical and uniform structure [25]. Taufiq-Yap and Lee reported similar observations [20]. They showed that sol-gel catalysts were characterised by better homogeneity and phase purity with sintering at low temperatures $\left(\leq 200^{\circ} \mathrm{C}\right)$, as opposed to the co-precipitated catalyst often described as lower phase purity catalysts [25]. 



Figure 2. SEM results of the prepared catalyst $\left(\mathrm{A}: \mathrm{CMCO}_{1} / \mathbf{B}: \mathrm{CMCO}_{2} / \mathbf{C}: \mathrm{CMCO}_{3} / \mathbf{D}: \mathrm{CMSG}_{1} / \mathbf{E}\right.$ : $\left.\mathrm{CMSG}_{2} / \mathbf{F}: \mathrm{CMSG}_{3}\right)[\mathrm{EHT}=5.00 \mathrm{keV}, \mathrm{WD}=4.7 \mathrm{~mm}, \mathrm{Mag}=5.00 \mathrm{KX}, 20 \mathrm{~nm}$ scale $]$.
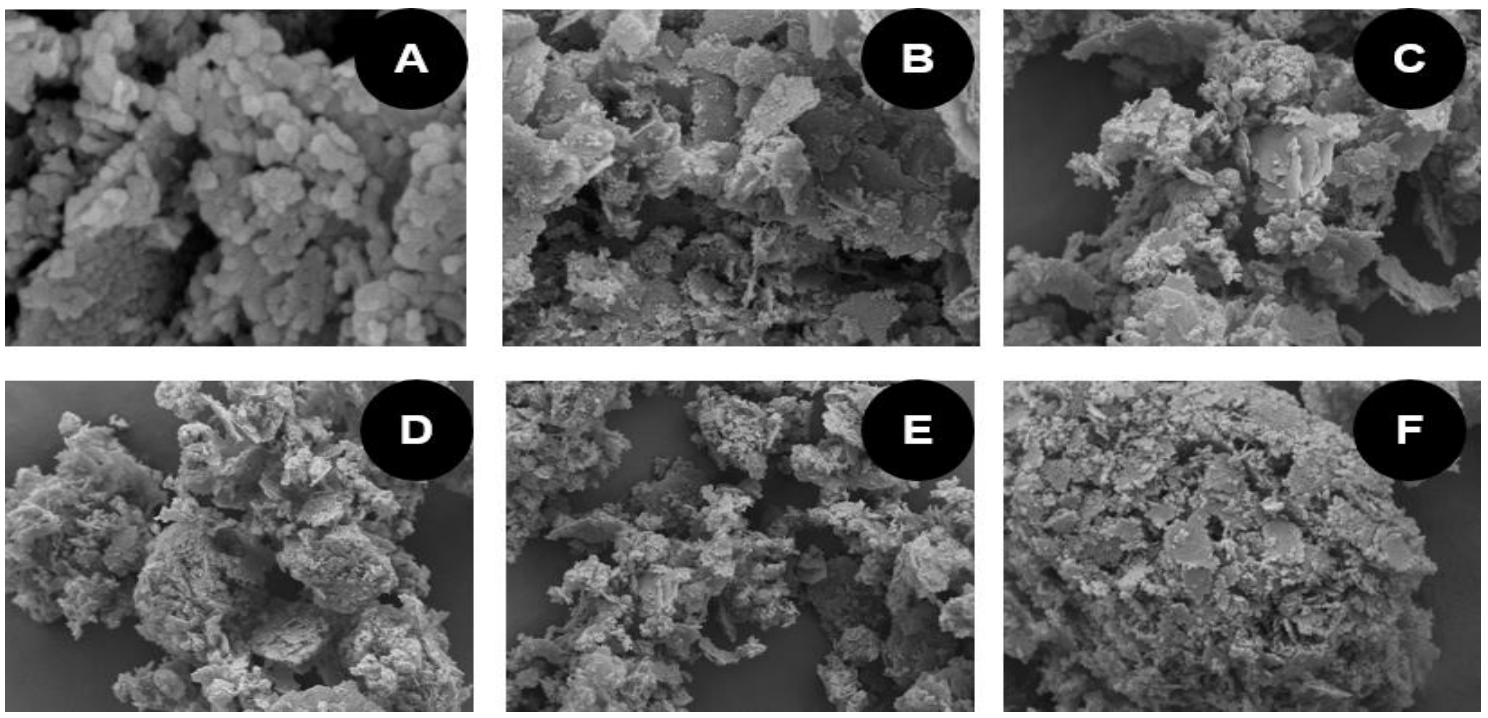

Figure 3. TEM results of the prepared catalyst $\left(\mathrm{A}: \mathrm{CMCO}_{1} / \mathbf{B}: \mathrm{CMCO}_{2} / \mathbf{C}: \mathrm{CMCO}_{3} / \mathbf{D}: \mathrm{CMSG}_{1} / \mathbf{E}\right.$ : $\left.\mathrm{CMSG}_{2} / \mathrm{F}: \mathrm{CMSG}_{3}\right)[\mathrm{EHT}=5.00 \mathrm{keV}, \mathrm{WD}=4.7 \mathrm{~mm}, \mathrm{Mag}=5.00 \mathrm{KX}, 200 \mathrm{~nm}$ and $1 \mu \mathrm{m}$ scale $]$.

Large pores separated the $\mathrm{CaO}$ and $\mathrm{MgO}$ aggregates in the CMCOs samples (Figure 3). An approximate quantification of $\mathrm{CMSG}_{3}$ samples indicated that the size of aggregates, as well as the width of pores between those aggregates, were in the range of 16 to $17 \mathrm{~nm}$ in comparison to 15 to $17 \mathrm{~nm}$ for the CMSG samples. For the catalysts that were prepared by the sol-gel technique (Figure 3F), there was a clear indication of localisation of metal nanoparticles in very small pores of the support structure. Farooq et al. [9] and Rahstizadeh et al. [28] reported a similar observation. Additionally, there was a uniform material contrast, justifying the clear visibility of calcium and iron as compared to magnesium based on a single peak that was represented in the spectrum (Figure 3).

The $\mathrm{pH}$ was increased from $\mathrm{CMCO}_{1}$ to $\mathrm{CMCO}_{3}$ by decreasing the $\mathrm{HNO}_{3}$ concentration from $1.5 \mathrm{M}$ to $0.5 \mathrm{M}$. Alhassan et al. [30] suggested that $\mathrm{pH}$ decreases before reaction completion might adversely affect the precipitation stage of the metal oxide catalyst, so the $\mathrm{pH}$ was carefully monitored. The $\mathrm{pH}$ adjustment was carried out in an attempt to enhance co-precipitation, which is favoured in 
a more alkaline environment. The optimum concentration was $1 \mathrm{M} \mathrm{HNO}_{3}$ for the $\mathrm{CMCO}_{2}$ catalyst. It was unclear why the microscopic characteristics and surface area of $\mathrm{CMCO}_{3}$ were inferior to those of $\mathrm{CMCO}_{2}$. The increase in ethylene glycol concentration positively contributed to the good quality of the gel that was obtained using the CMSG method (Figure 3F). This agrees with the reports by Zebarjad et al. [31]. In their study, high purity $\mathrm{MgO}$ sol-gel particles were synthesised with sizes that ranged from $30 \mathrm{~nm}$ to several $\mu \mathrm{m}$. The optimal CMSG catalyst exhibited more desirable structural properties than its $\mathrm{CMCO}$ counterpart, being more agglomerated and interconnected (Figure 3D-F).

\subsection{Magnetic Susceptibility and Mass Magnetisation Calculations}

In order to quantify the sample's magnetic strength, the magnetic susceptibility of each catalyst sample was converted into mass magnetisation using Gouw's principle $[8,10]$ (Table 2). The CMCO sample exhibited higher magnetic than the CMSG catalyst. This might be attributed to (i) the presence of iron originating from the magnetite in the sample and/or (ii) the size of the catalysts, which were smaller than the super paramagnetic critical size of $27 \mathrm{~nm}$, as described by Zebarjad et al. [31]. There was no major hysteresis in the magnetisation for either sample, which suggests that the particles were paramagnetic.

The CMSG samples were coupled to ZVINPs to boost the saturation magnetisation of the CMSG catalyst while conserving the optimum surface area for mass transfer. Maximum and minimum mass magnetisations were obtained for $\mathrm{CMSG}_{3} / \mathrm{ZVINPs}_{2}(173 \mathrm{emu} / \mathrm{g})$ and $\mathrm{CMSG}_{3}(84 \mathrm{emu} / \mathrm{g})$, respectively, indicating that the magnetic separation and regeneration of $\mathrm{CMSG}_{3} / \mathrm{ZVINPs}_{2}$ would be most favourable.

In this study, paramagnetism was confirmed by demonstrating that the catalyst particles in a bottle were attracted to a neodymium magnet outside the bottle. Paramagnetism (i.e., responsiveness to an applied magnetic field without permanent magnetisation) was an essential property, because it allowed for the $\mathrm{CMSG}_{3} / \mathrm{ZVINPs}_{2}$ to be separated from the mixture of biodiesel and glycerol under an external magnetic field, which was coupled with electrostatic separation to improve the sedimentation of glycerol.

\subsection{Evaluation of Catalytic Performance}

Biodiesel obtained from the transesterification process mediated by the $\mathrm{CMSG}_{3} / \mathrm{ZVINPs}_{2}$ catalyst was analysed to assess its quality. As previously described [23], the biodiesel was complied with selected standard specifications (Table 3).

Table 3. Comparison of the synthesised biodiesel (obtained using $\mathrm{CMSG}_{3} / \mathrm{ZVINPs}_{2}$ ) quality and the commercial diesel [23].

\begin{tabular}{ccccc}
\hline Properties & Unit & $\begin{array}{c}\text { Measurement } \\
\text { Standards }\end{array}$ & $\begin{array}{c}\text { Commercial Diesel } \\
\text { (50ppm Sulphur) }\end{array}$ & Biodiesel [23] \\
\hline Viscosity at $40{ }^{\circ} \mathrm{C}$ & $\mathrm{m}^{2} / \mathrm{s}$ & ASTM D445 & $3.0^{*} 10^{-6} \pm 0.87$ & $3.7 * 10^{-6} \pm 0.71$ \\
Density at $15^{\circ} \mathrm{C}$ & $\mathrm{kg} / \mathrm{m}^{3}$ & ASTM D941 & $830.0 \pm 0.78$ & $832.62 \pm 0.69$ \\
$\mathrm{HHV}$ & $\mathrm{M} / \mathrm{kg}$ & ASTM D2015 & $48.12 \pm 1.59$ & $45.75 \pm 1.21$ \\
Flash point & ${ }^{\circ} \mathrm{C}$ & ASTM D93 & $50.4 \pm 0.73$ & $61.3 \pm 0.64$ \\
\hline
\end{tabular}

Results are expressed as averages \pm standard deviation $(n=2)$.

Selected catalysts were used to produce biodiesel, and regenerated over four reaction cycles (Figure 4A-D). All of the catalysts were able to mediate biodiesel production (83-88\%) up until the fourth reaction cycle. In the case of the catalysts that were not coupled with ZVINPs, the biodiesel yield that was obtained using $\mathrm{CMCO}_{2}$ (Figure $4 \mathrm{~A}$ ) decreased from a maximum of $88 \%$ biodiesel yield to a minimum of $64 \%$. In contrast, $\mathrm{CMSG}_{3}$ exhibited the worst performance (Figure $4 \mathrm{~B}$ ), losing $39 \%$ of its activity after four transesterification cycles. This indicated that the co-precipitation method yielded a more robust catalyst than the sol-gel method in this instance. The hydride catalysts (CMSG/ZVINPs) showed an enhancement in performance (Figure 4C,D) over the CMSG catalyst. This was attributed to 
the enhanced mass magnetisation (Table 2) that was conferred by the ZVINPs. Factors, such as loss of catalyst during the separation [32], catalyst surface saturation [11,19], and catalyst leaching, are likely to have contributed to the reduction in the biodiesel yield [9] when using the regenerated catalysts.


Figure 4. (A) Recycled $\mathrm{CMCO}_{2}$; (B) $\mathrm{CMSG}_{3} ;$ (C) $\mathrm{CMSG}_{3} / \mathrm{ZVINPs}_{2}$; and, (D) $\mathrm{CMSG}_{3} / \mathrm{ZVINPs}_{3}$. Effect on the biodiesel yield (Error bars represent the standard deviation from the mean $(n=3))$.

Vishal et al. [33] investigated the use of $n$-hexane to improve the catalytic activity of the catalyst that was used to convert jatropha oil into biodiesel. A reduction in biodiesel yield from 98 to $89 \%$ after 
five reaction cycles was attributed to the loss of catalyst material during the separation process and the oversaturation of the catalyst's pores. Devarapaga et al. [34] described a decrease in biodiesel yield during three reaction cycles when using a novel $\beta$-tricalcium phosphate catalyst; the authors attributed the loss in performance to a high FFA concentration in the feedstock that neutralised the functional basic sites of the catalyst. In this instance, the catalyst efficiency was affected by the ability of that particular catalyst to influence the reaction rate, the biodiesel yield through the transesterification process, as well as the extent to which the catalyst could be regenerated while conserving its catalytic activity for biodiesel production. While the sol-gel method was easier to perform and less time consuming, and it resulted in a catalyst with good specific surface areas, the biodiesel yield was negatively affected. This could be due to the lower stability of CMSGs during the reaction. The catalyst sample could have disaggregated when stirring was applied into the vessel [34].

\section{Materials and Methods}

\subsection{Materials}

Sodium hydroxide pellets ( $98 \%$ ), anhydrous hexane (95\%), sodium chloride (anhydrous $\geq 99 \%$ ), anhydrous ethylene glycol $\left(\mathrm{C}_{2} \mathrm{H}_{6} \mathrm{O}_{2}\right)(99 \%)$, ferric sulphate, sodium borohydride, and nitric acid $(70 \%)$ used in this study were obtained from Sigma Aldrich (Sigma-Aldrich, St Louis, MO, USA), distilled water. Gangue material was obtained from a mineral processing plant in the Rustenburg region (South Africa) from cupriferous minerals that were generated from the concentration (floatation process) of sulfide ores.

\subsection{Catalyst Preparation}

The gangue sample that originated from cupriferous mineral processing was obtained from the outlet of bulk oil flotation cells and these samples were characterised by EDX to identify the phases and unit cell dimensions in the samples. This was then subjected to the different catalyst synthesis methods, as described in Sections 3.2.1-3.2.3.

\subsubsection{Sol-gel Method}

The catalyst was prepared following the method described by Chen et al. [25] with the following modifications: $10 \mathrm{~g}$ of gangue was dissolved in warm $\left(60^{\circ} \mathrm{C}\right) 1 \mathrm{~mol} / \mathrm{L}$ nitric acid $\left(\mathrm{HNO}_{3}\right)$ into a $500 \mathrm{~cm}^{3}$ beaker. The slurry was placed into an evaporative basin until crystals were formed. Nine g of the crystals were dissolved in $100 \mathrm{~mL}$ of distilled water, added to $15 \mathrm{~mL}$ of $\mathrm{C}_{2} \mathrm{H}_{6} \mathrm{O}_{2}$ to obtain catalyst $\mathrm{CMSG}_{1}$, to $20 \mathrm{~mL}$ of $\mathrm{C}_{2} \mathrm{H}_{6} \mathrm{O}_{2}$ to obtain catalyst $\mathrm{CMSG}_{2}$, and to $25 \mathrm{~mL}$ of $\mathrm{C}_{2} \mathrm{H}_{6} \mathrm{O}_{2}$ to synthesise catalyst $\mathrm{CMSG}_{3}$. The mixing time for all the catalysts was kept constant at $2 \mathrm{~h}$. During mixing, drops of $2 \mathrm{M}$ $\mathrm{NaOH}$ was added until a clear white gel was obtained. The gel was then kept static for $2 \mathrm{~h}$ for the reaction to complete, and then washed with distilled water. After filtration using Whatman's filter paper PTFE (pore size $0.5 \mu \mathrm{m}$ ), the washed, $\mathrm{pH}$-adjusted gel $(\mathrm{pH}=10)$ was dried by heating $20^{\circ} \mathrm{C}$ for $2 \mathrm{~h}$ and then placed in a desiccator for $1 \mathrm{~h}$. The dry gel was milled to form a white powder, which was decarbonised by gradually heating to $800^{\circ} \mathrm{C}$ in an oven.

\subsubsection{Co-precipitation Method}

Three CMCO catalysts were prepared using the co-precipitation method that was adapted from $\mathrm{Lu}$ et al. [35] based on different hematite-double nitrate of calcium and magnesium ratios $\left[\left(\mathrm{Fe}_{3} \mathrm{O}_{4}\right) /(\mathrm{Ca}, \mathrm{Mg})\left(\mathrm{NO}_{3}\right)_{2}\right]$ samples were accordingly labelled as $\mathrm{CMCO}_{1}$ (1:2); $\mathrm{CMCO}_{2}$ (1:3); and, $\mathrm{CMCO}_{3}$ (1:4). The $\mathrm{Fe}_{3} \mathrm{O}_{4}$ value was varied to investigate the enhancement of the magnetic susceptibility of the catalyst for separation purposes 


\subsubsection{Catalyst Mixed with Zero-Valent Iron Nanoparticles (ZVINPs)}

ZVINPs were prepared according to the stoichiometry shown in Equation (1) using the sulphate method [27]; $0.5 \mathrm{M}$ sodium borohydride was added to an equal volume of $0.28 \mathrm{M}$ ferrous sulphate at $0.15 \mathrm{~L} / \mathrm{min}$.

$$
2 \mathrm{Fe}^{2+}{ }_{(\mathrm{aq})}+\mathrm{BH}_{4}^{-{ }_{(\mathrm{aq})}}+3 \mathrm{H}_{2} \mathrm{O}_{(\mathrm{l})} \rightarrow 2 \mathrm{Fe}_{(\mathrm{s})}+\mathrm{H}_{2} \mathrm{BO}_{3}{ }^{-}{ }_{(\mathrm{aq})}+4 \mathrm{H}^{+}{ }_{(\mathrm{aq})}+2 \mathrm{H}_{2(\mathrm{~g})}
$$

The $\mathrm{CMSG}_{3}$ catalyst was then mixed with ZVINPs to form a hybrid catalyst. Three catalysts were obtained depending on the mixing ratio: $\mathrm{CMSG}_{3} / \mathrm{ZVINPs}_{1}$ (2:1), $\mathrm{CMSG}_{3} / \mathrm{ZVINPs}_{2}$ (3:1), and $\mathrm{CMSG}_{3} / Z V I N P s_{3}(4: 1)$. CMSG catalysts were amalgamated with ZVINPs to improve their magnetic susceptibility for separation purposes. In theory, magnetic separation can reduce the production costs by eliminating the need for more expensive separation methods, such as centrifugation. CMCO catalysts were not amalgamated with ZVINPs, because the co-precipitation method was significantly longer.

\subsection{Biodiesel Production and Separation}

Biodiesel was produced through a transesterification reaction using oil extracted from edible oil wastewater sludge and bioethanol (originating from the edible oil wastewater sludge residues after oil extraction). The process was separately mediated using different catalysts $\left(\mathrm{CMCO}_{2}, \mathrm{CMSG}_{3}\right.$, $\mathrm{CMSG}_{3} / \mathrm{ZVINPs}_{2}$, and $\left.\mathrm{CMSG}_{3} / Z V I N{ }_{3}\right)$, as previously described $[23,24]$. The triglycerides extracted from waste that was mainly contained monounsaturated fats. The catalysts were $\mathrm{CaO}$ and $\mathrm{MgO}-$ based. The use of these two compounds are known to result in higher biodiesel yield, at faster reaction rates, lower temperatures, and low catalyst loading $[8,21,23,24]$. The transesterification process was carried out in a $500 \mathrm{~mL}$ flask using a 1:6 oil/ethanol molar ratio and catalyst dosages were selected at 3, 5 , and $8 \mathrm{wt} . \%$. The temperature was set at $75{ }^{\circ} \mathrm{C}$ for $2 \mathrm{~h}$. All of the runs were performed in triplicate. After the reaction was completed, the collected catalyst was washed with ethanol and then dried at $80^{\circ} \mathrm{C}$ for $2 \mathrm{~h}$ before being used.

The electrostatic method was used to separate the biodiesel from the glycerol using LG electronics Neon transformer (Seoul, South Korea). The transformer electrodes were immersed in a flask containing $1 \mathrm{~L}$ biodiesel/glycerol mixture. The transformer was then set at $8 \mathrm{kV}$ and adjusted for $25 \mathrm{~mA}$. This separation process was completed after $20 \mathrm{~min}$. This technique was adapted from Mayvan et al. [36].

The yield of biodiesel obtained was calculated using Equations (2) and (3) relating the weight of oil in the raw material and the weight of biodiesel obtained after glycerol separation. These findings were compared with the values that were obtained using a GC-FID 6980A that was manufactured by Agilent (Santa Clara, CA, USA). The column used was a HP88 $(60 \mathrm{~m} \times 150 \mu \mathrm{m}, 0.250 \mu \mathrm{m})$ manufactured by Agilent Technologies (Santa Clara, CA, USA).

$$
\begin{gathered}
\text { Yield }(\%)=\frac{\text { Weight }_{\text {Biodiesel }}}{\text { Weight }_{\text {Oil }}} \times 100 \\
\text { Conversion }(\%)=\frac{\text { Weight }_{\text {Glycerol }- \text { Weight }_{\text {Biodiesel }}}}{\text { Weight }_{\text {Biodiesel }}} \times 100
\end{gathered}
$$

\subsection{Recovery of Catalyst from Biodiesel}

A magnetic field that was provided by a lightweight $(75 \mathrm{~g})$ neodymium magnet assembly with a $2 \mathrm{~cm}$ air gap and magnetic field of approximately $0.22 \mathrm{~T}$ (Tesla) was used to recover the catalyst. This magnet assembly was immersed into the flasks containing $500 \mathrm{~mL}$ biodiesel at ambient temperature for $10 \mathrm{~min}$, while stirring at $50 \mathrm{rpm}$. The collected catalyst was then washed with ethanol and then dried in an oven at $80^{\circ} \mathrm{C}$ for $2 \mathrm{~h}[23,24]$. 


\subsection{Catalyst Characterisation and Performance}

The morphology and particle sizes of the raw materials, as well as the catalysts, were assessed by EDX (STADI P, STOE model, Darmstadt, Germany). An Auriga (Carl Zeiss model, Jena, Germany). High-resolution scanning electron microscope (HRSEM) was used with a resolution of $1.5 \mathrm{~nm}$ to provide details from a focused electron beam across the surface of the sample. These images were magnified using an Auriga TF 20 high-resolution transmission electron microscope (Carl Zeiss model, Jena, Germany) with a resolution of $0.25 \mathrm{~nm}$ for $45 \mathrm{~min}$. to $2 \mathrm{~h}$ for sample mapping and imaging. Furthermore, an Aztec series (Hitachi High-Technologies, Tokyo, Japan) TM 4000 energy dispersive X-ray analyser with a $30 \mathrm{~mm}^{2}$ detector) was employed to provide the elemental identification and quantitative composition of the prepared catalyst. Catalyst surface areas were studied using a VF-Sorb 2400CE BET (Brunauer-Emmett-Teller) surface area analyser (Beijing, China). The magnetic susceptibilities of the catalysts were calculated based on Gouw's principle [32]. These results were confirmed by the PS PRO Gauss meter (Corby, United Kingdom). The performance of these catalysts was evaluated based on their abilities to improve the yield of biodiesel that is produced from edible oil wastewater sludge at different catalyst dosages (3,5, and $8 \mathrm{wt} . \%)$ and ethanol-oil ratios (3:1, 6:1, and 9:1), respectively. The particle surface area was confirmed using BET analysis.

\section{Conclusions}

The catalysts that were obtained from cupriferous mineral processing wastes were successfully prepared and characterised using TEM, SEM, EDX, and BET. The mass magnetisation analysis showed that the nanocatalyst samples were magnetic. The quality of the CMSG catalysts was not affected by the increase in ethylene glycol concentrations. Further, as for the catalysts that were prepared using the co-precipitation method CMCO, the magnetite ratio chosen in this study did not considerably increase their respective mass magnetisation. The reusability of the catalyst preparation over four cycles of transesterification reaction has the potential to reduce the cost of biodiesel production. The maintenance of $50-72 \%$ catalytic activities, as demonstrated by the biodiesel yields, after four cycles suggest that the catalysts can be used for more cycles. Properties of the biodiesel that were produced from the edible oil wastewater sludge using these catalysts were within the biodiesel standard specifications.

Author Contributions: Conceptualisation and validation, W.I.N., O.O.O., P.J.W.; methodology and software, W.I.N.; Formal analysis, W.I.N., P.J.W., O.O.O., D.I.-O.; Writing-Original draft preparation, W.I.N., P.J.W. and O.O.O.; writing-review and editing, W.I.N., P.J.W. and O.O.O.; supervision, P.J.W., O.O.O. and D.I.O.; project administration W.I.N., P.J.W., O.O.O. and D.I.-O.

Funding: The authors wish to extend their sincere appreciation to the Water Research Commission of South Africa (WRC-Project K5/2404) and the Council for Scientific and Industrial Research (CSIR/HCD-IBS programme) for funding this project. The content does not necessarily reflect the views and policies of the funding organisations.

Acknowledgments: The authors would also like to acknowledge the Department of Chemical Engineering for additional facility to conduct the research at the Cape Peninsula University of Technology (CPUT); Agrifood Station at the Department of Food Technology (CPUT) for wastewater analysis; The Department of Physics at the University of Western Cape (UWC) for the catalyst characterisation.

Conflicts of Interest: The authors declare no conflict of interest. The content does not necessarily reflect the views and policies of the funding organisations.

\section{References}

1. Cabri, L.J.; Rudashevsky, N.S.; Rudashevsky, V.N. Current approaches for the process mineralogy of platinum-group element ores and tailings. In Proceedings of the Ninth International Congress for Applied Mineralogy (ICAM 2008), Kerala State, India, 18-21 February 2008; Volume 8, pp. 9-17. [CrossRef]

2. Arens, V.Z.; Chernyak, S.A. Hydrometallurgy in the mining industry. Metallurgist 2008, 52, 3-10. [CrossRef]

3. Cairncross, B. History of the Okiep Copper District, Namaqualand, Northern Cape Province, South Africa. Mineral. Rec. 2004, 35, 289-317. [CrossRef]

4. Demirbas, A. Biodiesel Fuels from Vegetable Oils via Catalytic and Non-Catalytic Supercritical Alcohol Transesterifications and Other Methods: A Survey. Energy Convers. Manag. 2003, 44, 2093-2109. [CrossRef] 
5. Chen, S.Y.; Mochizuki, T.; Abe, Y.; Toba, M.; Yoshimura, Y. Ti-incorporated SBA-15 mesoporous silica as an efficient and robust Lewis solid acid catalyst for the production of high-quality biodiesel fuels. Appl. Catal. B Environ. 2014, 148, 344-356. [CrossRef]

6. $\mathrm{Hu}, \mathrm{S}$; Guan, H.; Wang, Y.; Han, H. Nano-magnetic catalyst $\mathrm{KF} / \mathrm{CaO}-\mathrm{Fe}_{3} \mathrm{O}_{4}$ for biodiesel production. Appl. Energy 2011, 88, 2688. [CrossRef]

7. Montero, J.M.; Brown, R.; Gai, P.L.; Lee, A.F.; Wilsonc, K. In situ studies of structure-reactivity relations in biodiesel synthesis over nanocrystalline MgO. Chem. Eng. J. 2010, 161, 332-336. [CrossRef]

8. Amani, H.; Ahmad, Z.; Hameed, B.H. Synthesis of fatty acid methyl esters via the methanolysis of palm oil over Ca3.5xZr0.5yAlxO 3 mixed oxide catalyst. Renew. Energy 2014, 66, 680-685. [CrossRef]

9. Farooq, M.; Ramli, A.; Subbarao, D. Biodiesel production from waste cooking oil using bifunctional heterogeneous solid catalysts. J. Clean. Prod. 2013, 59, 131-140. [CrossRef]

10. Elfimov, I.S.; Yunoki, S.; Sawatzky, G.A. Possible path to a new class of ferromagnetic and half-metallic ferromagnetic materials. Phys. Rev. Lett. 2002, 89, 216403. [CrossRef]

11. Mardhiah, H.H.; Ong, H.C.; Masjuki, H.H.; Lim, S.; Lee, H.V. A review on latest developments and prospects of heterogeneous catalyst in biodiesel production from non-edible oils. Renew. Sustain. Energy. Rev. 2017, 67, 1225-1236. [CrossRef]

12. Konaka, A.; Tago, T.; Yoshikawa, T.; Shitara, H.; Nakasaka, Y.; Masuda, T. Conversion of biodiesel-derived crude glycerol into useful chemicals over a zirconia-iron oxide catalyst. Ind. Eng. Chem. Res. 2013, 52, 15509-15515. [CrossRef]

13. Bobade, V.V.; Kulkarni, K.S.; Kulkarni, A.D. Application of Heterogeneous Catalyst for the Production of Biodiesel. Int. J. Adv. Eng. Technol. 2011, 2, 184-185. [CrossRef]

14. Gao, X.; Yu, K.M.K.; Tam, K.Y.; Tsang, S.C. Colloidal stable silica encapsulated Nanomagnetic composite as a novel bio-catalyst carrier. Chem. Commun. 2003, 24, 2998. [CrossRef] [PubMed]

15. Wen, L.B.; Wang, Y.; Lu, D.L.; Hu, S.Y.; Han, H.Y. Preparation of KF/CaO nanocatalyst and its application in biodiesel production from Chinese tallow seed oil. Fuels 2010, 89, 2267. [CrossRef]

16. Ying, M.; Chen, G. Study on the production of biodiesel by magnetic cell biocatalyst based on lipase-producing Bacillus subtilis. Appl. Biochem. Biotechnol. 2007, 137, 793-803. [CrossRef]

17. Xie, W.; Ma, N. Immobilized lipase on $\mathrm{Fe}_{3} \mathrm{O}_{4}$ nanoparticles as biocatalyst for biodiesel production. Energy Fuels 2009, 23, 1347. [CrossRef]

18. Ali, M.A.; Al-Hydary, I.A.; Al-Hattab, T.A. Nano-Magnetic Catalyst $\mathrm{CaO}-\mathrm{Fe}_{3} \mathrm{O}_{4}$ for Biodiesel Production from Date Palm Seed Oil. Bull. Chem. React. Eng. Catal. 2017, 12, 460-468. [CrossRef]

19. Di Serio, M.; Tesser, R.; Pengmei, L.; Santacesaria, E. Heterogeneous catalysts for Biodiesel production. Energy Fuels 2008, 207, 17-22. [CrossRef]

20. Taufiq-Yap, Y.H.; Teo, S.H.; Rashid, U.; Islam, A.; Hussien, M.Z.; Lee, K.T. Transesterification of Jatropha curcas crude oil to biodiesel on calcium lanthanum mixed oxide catalyst: Effect of stoichiometric composition. Energy Convers. Manag. 2014, 88, 1290-1296. [CrossRef]

21. Kouzu, M.; Kajita, A.; Fujimori, A. Catalytic activity of calcined scallop shell for rapeseed oil transesterification to produce biodiesel. Fuels 2016, 182, 220-226. [CrossRef]

22. Marinkovic, D.M.; Avramovic', J.M.; Stankovic, M.V.; Stamenkovic, O.S.; Jovanovića, D.M.; Veljković, V.B. Synthesis and characterization of spherically-shaped $\mathrm{CaO} / \gamma-\mathrm{Al}_{2} \mathrm{O}_{3}$ catalyst and its application in biodiesel production. Energy Convers. Manag. 2017, 144, 399-413. [CrossRef]

23. Ngoie, I.W.; Welz, P.J.; Oyekola, O.O.; Ikhu-Omoregbe, D. Valorisation of edible oil wastewater sludge: Bioethanol and biodiesel production. Waste Biomass Valorization 2019. [CrossRef]

24. Ngoie, W.I.; Welz, P.J.; Oyekola, O.O.; Ikhu-Omoregbe, D.I. Qualitative Assessment of Biodiesel Produced from Primary Edible Oil Wastewater Sludge. Waste Biomass Valorization 2019. [CrossRef]

25. Di Serio, M.; Cozzolino, M.; Giordano, M.; Tesser, R.; Patrono, P.; Santacesaria, E. From homogeneous to heterogeneous catalysts in biodiesel production. Ind. Eng. Chem. Res. 2007, 46, 6379-6384. [CrossRef]

26. Chen, H.; Zhang, P.; Duan, Y.; Zhao, C. Reactivity enhancement of calcium based sorbents by doped with metal oxides through the sol-gel process. Appl. Energy 2016, 162, 390-400. [CrossRef]

27. Coulson, J.M.; Richardson, J.F. Coulson's and Richardson's Chemical Engineering Handbook; Chhabra, R.P., Gurappa, B., Eds.; Oxford: Butterworth-Heinemann, UK, 2002.

28. Rashtizadeh, E.; Farzaneh, F.; Talebpour, Z. Synthesis and characterization of $\mathrm{Sr}_{3} \mathrm{Al}_{2} \mathrm{O}_{6}$ nanocomposite as catalyst for biodiesel production. Bioresour. Technol. 2014, 154, 32-37. [CrossRef] [PubMed] 
29. Hu, S.; Guan, Y.; Wang, Y.; Han, H. Nano-magnetic catalyst $\mathrm{KF} / \mathrm{CaO}-\mathrm{Fe}_{2} \mathrm{O}_{3}$ for biodiesel production. Appl. Energy 2011, 88, 2685-2690. [CrossRef]

30. Xie, W.; Fan, M. Biodiesel production by transesterification using tetraalkylammonium hydroxides immobilized onto SBA-15 as a solid catalyst. Chem. Eng. J. 2014, 239, 60-67. [CrossRef]

31. Teo, S.H.; Rashid, U.; Taufiq-Yap, Y.H. Biodiesel production from crude Jatropha Curcas oil using calcium based mixed oxide catalysts. Fuels 2014, 136, 244-252. [CrossRef]

32. Alhassan, F.H.; Rashid, U.; Taufiq-Yap, Y.H. Synthesis of waste cooking oil-based biodiesel via effectual recyclable bi-functional $\mathrm{Fe}_{2} \mathrm{O}_{3} \mathrm{MnOSO} 42-/ \mathrm{ZrO}_{2}$ nanoparticle solid catalyst. Fuels 2014, 142, 38-45. [CrossRef]

33. Lu, A.H.; Salabas, E.L.; Schiith, F. Magnetic nanoparticles: Synthesis, protection, functionalization, and application. Cheminternationale 2007, 46, 1222. [CrossRef] [PubMed]

34. Vishal, T. Biodiesel-An Alternative Method for Energy Crisis: A Review. J. Biol. Chem. Chron. 2016, 2, 14-26. [CrossRef]

35. Devarapaga, M.; Chavan, S.; Singh, V.; Singh, B.; Sharma, Y.C. An economically viable synthesis of biodiesel from a crude Millettia pinnata oil of Jharkhand, India as feedstock and crab shell derived catalyst. Bioresour. Technol. 2016, 214, 210-217. [CrossRef]

36. Mayvan, A.A.; Ghobadian, B.; Najafi, G. Electrostatic coagulation for separation of crude glycerin from biodiesel. Adv. Environ. Biol. 2014, 8, 321-324.

(C) 2019 by the authors. Licensee MDPI, Basel, Switzerland. This article is an open access article distributed under the terms and conditions of the Creative Commons Attribution (CC BY) license (http://creativecommons.org/licenses/by/4.0/). 